\title{
The passive person as a reinforcer in isolated beagle puppies'
}

\author{
Walter C. Stanley \\ NATIONAL INSTITUTE OF MENTAL HEALTH
}

\begin{abstract}
It is concluded from the findings that the passive person is a primary reinforcer. An hypothesis concerning the post-isolation behavioral syndrome and fear of the strange or unfamiliar is proposed.
\end{abstract}

\section{Problem}

Previous research (Stanley \& Elliot, 1962; Bacon \& Stanley, 1963; Stanley et al, 1965) has shown that the passive person is a reinforcer in puppies reared normally except for early weaning. In the present study the puppies' history contained no apparent correlation of people with food or with other primary homeostatic reinforcers. Positive findings in such Ss would indicate that a passive person is a primary reinforcer; negative findings, that it is secondary or learned.

\section{Method}

Three purebred beagles, 5838, 5841, and 5842, were housed from birth to 31 days of age in a 44- X 29- X 27in-high whelping box and fed only by their nursing on the bitch. When they were old enough to walk, a low partition was placed in the box to prevent their seeing, or interacting with, a person. From 31 days of age to the end of the experiment, each $\mathrm{S}$ was housed individually in a plywood shuttle box, which also was the experimental space. A 4 th $S$ (5835), littermate to the other 3, was housed and run the same way with one exception. It was handled and fed (HF) on an artificial nipple at only 0-2 days of age in another experiment.

Each shuttle box (12- X 21/4-X4-ft high) had a partition and guillotine door at its center. The end walls were hinged half way down and contained a one-way vision glass. Remotely controlled devices ${ }^{2}$ delivered food and water, air blowers provided ventilation, and motors operated the guillotine doors. Air of $75^{\circ} \mathrm{F}$ and $50 \% \mathrm{RH}$, theoretically, replaced air inside the boxes ca. every $2 \mathrm{~min}$. An air baffle and two $40-\mathrm{W}$ bulbs were in the ceiling, food and water pans on either side of the center wall, and wood shavings on the floor, of each compartment of each shuttle box. The light-dark cycle was 14 and $10 \mathrm{hr}$. during training. There was one switch for starting an electric timer and opening the guillotine door; a second, for lowering the door, stopping the first timer, and starting a second timer; and a third for stopping the second timer.

Training began when Ss were 55 days old and after 24 days of habituation in the shuttle boxes. There were 5 trials/day Mon. through Sat. for $6 \mathrm{wk}$. and Mon. through Fri. on the 7 th wk. Training was either with the person (P) or without the person (NP) and was conducted in the A.M. Remote food and water delivery came in the P.M. Two Ss, 5842 and 5835, received, in order, $30 \mathrm{P}$, $60 \mathrm{NP}, 30 \mathrm{P}$, and $85 \mathrm{NP}$, trials. The other $2 \mathrm{Ss}$ received $30 \mathrm{NP}, 60 \mathrm{P}, 51$ or 52 special P, 38 or $39 \mathrm{P}$, and $25 \mathrm{NP}$, trials. The $P$ was male for 5842 and 5841, female for 5835 and 5838.

On each regular trial, $P$ entered the empty side of the shuttle box, sat down cross-legged with his back against the end wall, and didn't talk. The E raised the guillotine door 20 sec. later, lowered it when $\mathrm{S}$ cleared the doorway, and stopped the second timer when Shad run $31 / 2$ $\mathrm{ft}$ into the goal side of the box. The $P$ left the box $1 \mathrm{~min}$. after S's 3 1/2-ft approach response or $10 \mathrm{~min}$. after the door had been raised, whichever came first. The next trial of the day began 1-1 1/2 min. later. On NP trials, the procedure differed in that $P$ left the shuttle box right after entering it, and at the trial's termination, the end door was opened and closed by E, as a mock exit. The mock exit was omitted on the last 25 NP trials of Ss 5842 and 5835 .

Two Ss, 5838 and 5841, failed to run during their initial $\mathrm{P}$ training. They then received 30 special trials with $\mathbf{P}$ sitting near the guillotine door and 21 and 22 trials with $\mathrm{P}$ entering the occupied compartment. On 3 of the latter trials, 5838 was chucked under the chin and addressed, "nice puppy" to elicit approach and interaction.

For each S, initial and running times on each trial were summed. Cumulative approach response frequency was then plotted on total time, accumulated over successive trials.
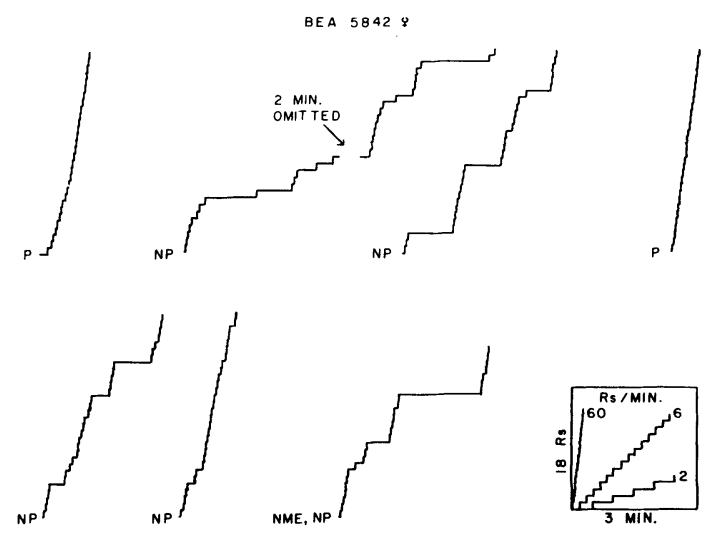

Fig. 1. Performance of isolated beagle 5842 during P, NP, and NP no mock exit (NME) trials. 


\section{Results}

The performance of 5842 stabilized quickly under $\mathrm{P}$, broke down under NP, stabilized again under $\mathrm{P}$, then broke down again under NP, trials (Fig. 1). Omission of the mock exit was correlated with some further impairment in performance.

The HF S performed comparably to 5842 , but improved, rather than declined, in the final NP trials (Fig. 2). The guillotine door struck this $\mathrm{S}$ on the first trial of the final NP series, which may account for the anomalous result.

The 2 Ss initially receiving NP, or operant, training emitted only a few approach responses, then. when $P$ was introduced, $1 \mathrm{~S}$ responded once in $10 \mathrm{hr}$. (60 trials) of training (Fig. 3). These Ss were uneasy and even frightened after the door was raised during their first series of $P$ trials. After special training, stable responding developed in both Ss, then broke down under the final NP trials.

\section{Discussion}

The 3 Ss which had no known correlation of any person with a primary homeostatic reinforcer attained stable performance (were conditioned) when $\mathrm{P}$ was present and declined in performance (showed extinction) when P was omitted. This finding indicates that a passive person is a primary reinforcer in the puppy.

The 2 Ss started on NP, or operant, training were striking in the swiftness which their initial locomotory behavior declined, and, when $\mathrm{P}$ was later introduced, in

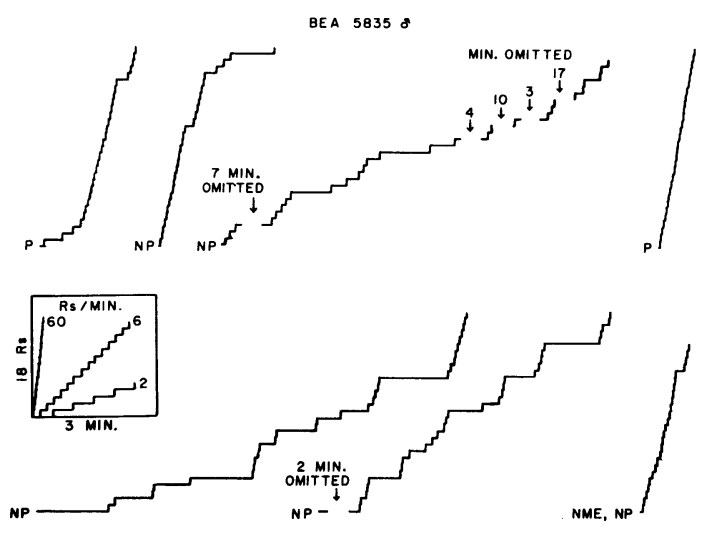

Fig. 2. Performance of $\mathrm{HF}$ isolated beagle 5835, during P, NP, and NP no mock exit (NME), trials.

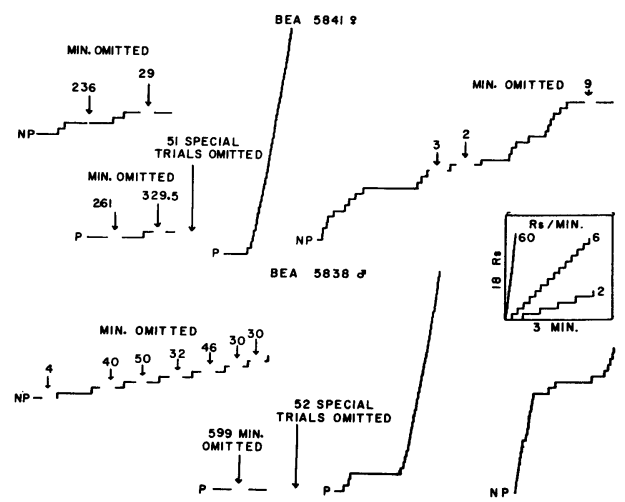

Fig. 3. Performance of isolated beagles 5841 and 5838 during $P$ and NP trials.

their uneasiness and fright. This finding may be, theoretically, the more important of the two main findings. A possible interpretation is that later introduction of $P$ was functionally equivalent to omission of customary visual stimulation previously contingent on S's visual behavior when the guillotine door was opened. Assuming that customary visual stimuli were reinforcers, it follows that later introduction of $P$ was equivalent to omission of positive reinforcers, hence the emotional behavior. This hypothesis may explain the emotional hypo- and hyper-activity of the post-isolation syndrome (Fuller, 1964). It may also explain fear of the strange or unfamiliar.

\section{References}

BACON, W. E., \& STANLEY, W. C. Effect of deprivation level in puppies on performance maintained by a passive person reinforcer. J. comp. physiol. Psychol., 1963, 56, 783-785.

FULLER, J. L. The K-puppies. Discovery, 1964, 25(2), 18-22. STANLEY, W. C., \& ELLIOT, O. Differential human handling as reinforcing events and as treatments influencing later social behavior in basenji puppies. Psychol. Rep., 1962, 10, 775-788. STANLEY, W. C., MORRIS, D. D., \& TRATTNER, A. Conditioning with a passive person reinforcer and extinction in Shetland sheep dog puppies. Psychon. Sci., 1965, 2, 19-20.

\section{Notes}

1. This research was done at the Jackson Laboratory and supported, in part, by PHS Grant M-4412 from the National Institute of Mental Health, Public Health Service. Gratitude is expressed to Stephen Schell, Thomas C. Snell, Anthony Hilton, and Martha Samuelson, for aid in the construction of apparatus and the running of Ss. A preliminary report of the experiment was presented at the 1964 meeting of the Psychonomic Society.

2. The devices, designed by Drs. R. L. Solomon and A. H. Black, were purchased from Harvard University. 